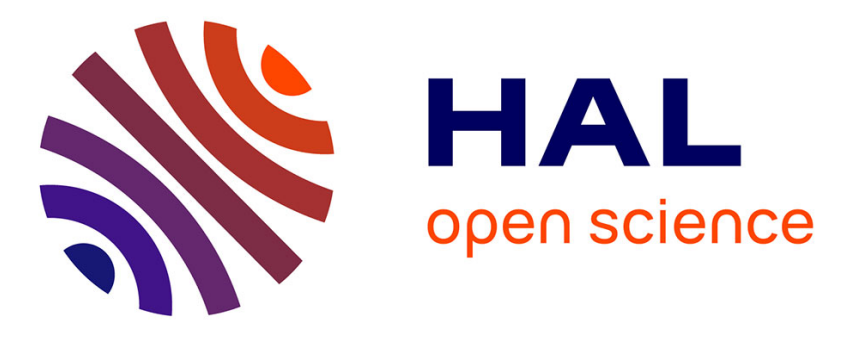

\title{
Repurposing bioactive aporphine alkaloids as efflux pump inhibitors
}

Fatma Gizem Avci, Basak Atas, Cemile Selin Aksoy, Eldin Kurpejovic, Gizem Gulsoy Toplan, Caglayan Gurer, Maxime Guillerminet, Cedric Orelle, Jean-Michel Jault, Berna Sariyar Akbulut

\section{To cite this version:}

Fatma Gizem Avci, Basak Atas, Cemile Selin Aksoy, Eldin Kurpejovic, Gizem Gulsoy Toplan, et al.. Repurposing bioactive aporphine alkaloids as efflux pump inhibitors. Fitoterapia, 2019, 139, pp.104371. 10.1016/j.fitote.2019.104371 . hal-02376192

\section{HAL Id: hal-02376192 \\ https://hal.science/hal-02376192}

Submitted on 18 Nov 2020

HAL is a multi-disciplinary open access archive for the deposit and dissemination of scientific research documents, whether they are published or not. The documents may come from teaching and research institutions in France or abroad, or from public or private research centers.
L'archive ouverte pluridisciplinaire HAL, est destinée au dépôt et à la diffusion de documents scientifiques de niveau recherche, publiés ou non, émanant des établissements d'enseignement et de recherche français ou étrangers, des laboratoires publics ou privés. 


\section{Repurposing bioactive aporphine alkaloids as efflux pump}

\section{inhibitors}

Fatma Gizem AVCI ${ }^{\mathrm{a}, *}$, Basak ATAS ${ }^{\mathrm{a}}$, Cemile Selin AKSOY ${ }^{\mathrm{a}}$, Eldin KURPEJOVIC ${ }^{\text {, }}$, Gizem

GULSOY TOPLAN ${ }^{\mathrm{b}}$, Caglayan GURER ${ }^{\mathrm{b}}$, Maxime GUILLERMINET $^{\mathrm{c}}$, Cedric ORELLE $^{\mathrm{c}}$, Jean-Michel JAULT ${ }^{\mathrm{c}}$, Berna SARIYAR AKBULUT ${ }^{\mathrm{a}}$

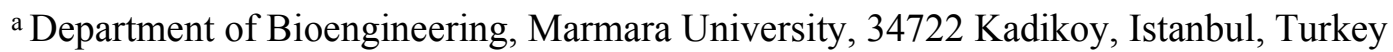

${ }^{\mathrm{b}}$ Department of Pharmacognosy, Faculty of Pharmacy, Istanbul University, Istanbul, Turkey

c University of Lyon, CNRS, UMR5086 “Molecular Microbiology and Structural

Biochemistry", IBCP, 7 Passage du Vercors, F-69367, Lyon, France

e-mail addresses:

basak.atas@yahoo.com.tr (B. Atas)

selinaksoy249@gmail.com (C. S. Aksoy)

eldin.kurpejovic@gmail.com (E. Kurpejovic)

gizem.toplan@istanbul.edu.tr (G. Gulsoy Toplan)

cunsal@istanbul.edu.tr (C. Gurer)

maxime.guillerminet@ibcp.fr (M. Guillerminet)

cedric.orelle@ibcp.fr (C. Orelle)

jean-michel.jault@ibcp.fr (J. M. Jault)

berna.akbulut@marmara.edu.tr (B. Sariyar Akbulut) 
*Corresponding Author:

Fatma Gizem Avci

Department of Bioengineering

Marmara University, 34722 Kadikoy

Istanbul, Turkey

E-mail: gizemavci@gmail.com

ORCID: 0000-0001-6618-0487

Current Address:

Department of Bioengineering

Uskudar University

Uskudar 34662, Istanbul - TURKEY

Phone: +9021640022 22

Fax: +902164741256 


\begin{abstract}
Extrusion of drugs or drug-like compounds through bacterial efflux pumps is a serious health issue that leads to loss in drug efficacy. Combinatorial therapies of low-efficacy drugs with efflux pump inhibitors may help to restore the activities of such drugs. In this quest, natural products are attractive molecules, since in addition to their wide range of bioactivities they may inhibit efflux pumps. The current work repurposed the bioactive alkaloid roemerine as a potential efflux pump inhibitor. In Bacillus subtilis, both $\mathrm{Bmr}$ and $\mathrm{BmrA}$, belonging to the major facilitator and the ATP-binding cassette superfamilies, respectively, were found to be inhibited by roemerine. Scanning electron microscopy and RNA-Seq analyses showed that it potentiated the effect of berberine. Growth rates and checkerboard assays confirmed the synergy of roemerine and berberine and that roemerine prevented berberine efflux by inhibiting Bmr. Transport assays with inverted membrane vesicles prepared from Escherichia coli overexpressing BmrA showed that increasing roemerine concentration decreased the transport of doxorubicin, the BmrA substrate, confirming that roemerine may also be considered as an inhibitor of BmrA. Thus, these findings suggest that conjugation of roemerine to substrates of efflux pumps, Bmr and BmrA, may help to potentiate the activity of their drug substrates.
\end{abstract}

Keywords: Efflux pump inhibition, alkaloid, roemerine, berberine, Bmr, BmrA. 


\section{Introduction}

Bacterial recognition of foreign molecules, such as drugs or drug-like compounds, leads to their extrusion through multidrug efflux pumps [1]. Minimization of the intracellular concentration of an antibacterial agent through the action of these pumps constitutes a serious health issue as it notably reduces the efficacy of the drugs used. The decrease in the pace of 'new antibacterial molecule discovery' raises interest to restore the activities of existing molecules by inhibiting the actions of efflux pumps. Thus, combinatorial therapies of drugs with efflux pump inhibitors (EPIs) have the potential to bring molecules of low efficacy back to the clinic.

Many natural products bear more than one biological activity as a consequence of their multitarget properties [2]. To date, a significant number of natural compounds have been reported to possess EPI properties [3], in addition to their known anti-bacterial, anti-fungal, antiinflammatory, anti-tumor, anti-oxidant, anti-depressant, anti-cancer, anti-diarrheal, cholagogue, hepatoprotective, and anti-diabetic activities [4]. These natural compounds include, but are not limited to, alkaloids such as reserpine and piperine, essential oils, phenolic metabolites such as silibinin, 5'-methoxy-hydnocarpin (5'-MHC), and catechin gallates [5-7]. Many reports have proven that, due to their multi-target properties, most of these molecules usually not only inhibit one but more than one pump in a cell [8]. Thus, finding the actual target might not be a trivial task, even after the establishment of the EPI activity.

The alkaloid reserpine of the indole family is among the first natural compounds to be identified as an EPI. Originally, it was known for its antipsychotic and antihypertensive drug activities. Later studies have shown that it also targets efflux pumps, such as BmrA [9], Bmr, NorA [10], PatA/PatB [11], and TetK [12] significantly enhancing the activities of antibacterial agents $[13,14]$. Based on the clues that many alkaloids possess a multi-target feature, we hypothesized that other alkaloids may act as EPIs in bacterial cells. Information that the aporphine alkaloid roemerine enhanced the cytotoxic response mediated by vinblastine due to its possible 
interaction with the eukaryotic efflux pump P-glycoprotein [15], has further motivated us to evaluate three structurally similar biologically active aporphine alkaloids (Fig. 1) as EPI candidates.

\begin{tabular}{lccccccc}
\hline \multicolumn{1}{c}{ Name } & $\mathbf{1}$ & $\mathbf{2}$ & $\mathbf{3}$ & $\mathbf{6}$ & $\mathbf{9}$ & $\mathbf{1 0}$ & $\mathbf{1 1}$ \\
\hline Boldine & $\mathrm{OCH}_{3}$ & $\mathrm{OH}$ & $\mathrm{H}$ & $\mathrm{CH}_{3}$ & $\mathrm{OH}$ & $\mathrm{OCH}_{3}$ & $\mathrm{H}$ \\
Roemerine & $-\mathrm{O}-\mathrm{CH}_{2}-\mathrm{O}-$ & $\mathrm{H}$ & $\mathrm{CH}_{3}$ & $\mathrm{H}$ & $\mathrm{H}$ & \\
Bulbocapnine & $-\mathrm{O}-\mathrm{CH}_{2}-\mathrm{O}-$ & $\mathrm{H}$ & $\mathrm{CH}_{3}$ & $\mathrm{H}$ & $\mathrm{OCH}_{3}$ & $\mathrm{OH}$
\end{tabular}

Fig. 1. Structures of alkaloids studied in this work.

These selected alkaloids display various biological activities by binding different targets, i.e. boldine has antioxidant, hepatoprotective, cytoprotective, antipyretic, and anti-inflammatory activities [16]; bulbocapnine inhibits acetylcholinesterase [17] and tyrosine hydroxylase activities [18] in addition to its involvement in the prevention of amyloid beta-protein fiber formation; roemerine acts as an inhibitor for CD45 protein tyrosine phosphatase [19] and exhibits antibacterial and antifungal activities [20]. Although these and many other alkaloids possess valuable bioactive properties, they may display cytotoxic properties when administered at their active concentrations. However, conjugation of these alkaloids as EPIs to other molecules may also help to reduce their effective concentrations.

The current study aimed to examine the EPI properties of selected alkaloids by observing the potentiation of the antibacterial activity of berberine when administered in combination with the selected EPI candidates. The antimicrobial berberine is a well-known substrate of efflux pumps and its activity is commonly impaired due to the activity of efflux pumps [21]. Thus, the synergistic activity of the alkaloid-berberine combinations will be sought in an attempt to find new EPIs. 


\section{Materials and methods}

\subsection{Bacterial strains}

Wild-type Bacillus subtilis 168 (DSM 402), B. subtilis $\Delta b m r$ [13], and B. subtilis $\Delta b m r A$ [9] were used for testing the EPI properties of alkaloids. Escherichia coli C41(DE3) cells were used for overexpression of BmrA in transport assays [22].

\subsection{Alkaloids used}

Berberine chloride hydrate (CAS No. 141433-60-5), boldine (CAS No. 476-70-0), (+)bulbocapnine hydrochloride (CAS No. 632-47-3) were obtained from Sigma-Aldrich. (-)Roemerine was isolated from Papaver syriacum Boiss. et Blanche. All alkaloids were dissolved in dimethyl sulfoxide (DMSO).

\subsection{Plant material and alkaloid extraction}

Papaver syriacum Boiss. et Blanche was collected from Hatay (southern part of Turkey) in June 2016 (altitude 724 m). Voucher specimens were identified by Şükran Kültür and are deposited in the Herbarium of the Faculty of Pharmacy, Istanbul University (ISTE NO: 110346).

Aerial parts of $P$. syriacum (200 g) were dried and extracted with $\mathrm{MeOH}$ and the extract was concentrated under reduced pressure. The residue was taken up in 5\% hydrochloric acid. The acid extract was first washed with light petroleum and then with diethyl ether. The aqueous layer was made alkaline with $\mathrm{NH}_{4} \mathrm{OH}$ to $\mathrm{pH}$ 7-8 and extracted successively with $\mathrm{CHCl}_{3}$. The combined $\mathrm{CHCl}_{3}$ extracts were dried over anhydrous $\mathrm{Na}_{2} \mathrm{SO} 4$, filtered and concentrated under vacuum to yield the tertiary alkaloid extracts. The tertiary alkaloid extract was separated on a column of silica gel (Kieselgel 60, 0.063-0.200 mm, 70-230 mesh) eluting with $\mathrm{CHCl}_{3}$ and $\mathrm{CHCl}_{3}: \mathrm{MeOH}(95: 5,90: 10,80: 20)$. Fractions were evaporated and purified by preparative thinlayer chromatography on silica gel to afford pure alkaloids. The solvent system used for preparative chromatography was cyclohexane:chloroform:diethylamine (7:2:1). Alkaloid roemerine was obtained in the pure form and gave a positive reaction to Dragendorff reagent 
which suggests the presence of an alkaloid. The identification of roemerine was carried out by comparing its $\mathrm{UV},{ }^{1} \mathrm{H}-\mathrm{NMR}$ spectral data with values described in literature and $\mathrm{TLC} \mathrm{R}_{\mathrm{f}}$ values with an authentic sample [23]. UV spectrum was taken with Jasco V-530 spectrophotometer and ${ }^{1} \mathrm{H}-\mathrm{NMR}$ spectra was recorded on a Varian Unity Inova $500 \mathrm{MHz}$ spectrometer. The UV spectrum of roemerine showed absorptions at 233, 264 (sh), 271, 285 (sh), $315 \mathrm{~nm}$, characteristic of aporphine alkaloids. The ${ }^{1} \mathrm{H}-\mathrm{NMR}$ spectrum showed typical signals for aporphine alkaloids at: $\left(\mathrm{CDCl}_{3}, 500 \mathrm{MHz}, \delta\right) 2.45 \mathrm{ppm}\left(3 \mathrm{H}, \mathrm{s}, \mathrm{N}-\mathrm{CH}_{3}\right), 5.85-6.00 \mathrm{ppm}(2 \mathrm{H}, \mathrm{dd}$, $-\mathrm{OCH}_{2} \mathrm{O}$ methylenes), 6.48 ppm (1H, s, C-3), 7.06-7.25 ppm (3H, m, C-8-9-10), 7.98 ppm $(1 \mathrm{H}, \mathrm{d}, \mathrm{C}-11) . \quad \mathrm{R}_{\mathrm{f}}$ values for roemerine were 0.79 in the solvent system cyclohexane:chloroform:diethylamine $(7: 2: 1)$ and 0.72 in cyclohexane:diethylamine $(8: 2)$.

\subsection{Bacterial growth conditions}

B. subtilis cells were grown in nutrient broth (NB, Merck, Germany) at $37{ }^{\circ} \mathrm{C}$ and $180 \mathrm{rpm}$ and treated with berberine $75 \mu \mathrm{g} \cdot \mathrm{mL}^{-1}$ and/or $25 \mu \mathrm{g} \cdot \mathrm{mL}^{-1}$ of different aporphine alkaloids. Drug treatment was achieved as $\mathrm{OD}_{600}$ of the culture broth reached $0.55 \pm 0.05$. Alkaloids were dissolved in DMSO and control cells were treated with an equal volume of DMSO. Bacterial growth was monitored at $\mathrm{OD}_{600}$.

\subsection{Total RNA isolation}

One-hour berberine $\left(75 \mu \mathrm{g} \cdot \mathrm{mL}^{-1}\right)$ and roemerine $\left(25 \mu \mathrm{g} \cdot \mathrm{mL}^{-1}\right)$ treated and control wild-type cells were placed in RNAprotect Bacteria Reagent (Qiagen, Germany) and incubated 5 minutes at room temperature. Cell suspensions were centrifuged at $5000 \mathrm{xg}$ for 10 minutes. Total RNA isolation was achieved using Qiagen RNeasy Mini Kit (Qiagen, Germany) with mechanical disruption at $6 \mathrm{~m} / \mathrm{s}$ for 40 seconds (FastPrep-24 Instrument, MP Biomedicals, USA). The quality of the samples was checked using Agilent 2100 bioanalyzer [24]. 


\subsection{Sequencing of $m R N A$}

RNA-Seq of the samples was performed at the Beijing Genomics Institute (BGI, Shenzhen, China). The library was constructed with paired-end sequencing using Illumina HiSeqTM 4000 technology.

\subsection{Analysis Pipeline}

Analysis of the raw data has been carried out using R [25,26], as outlined previously [24]. Taking B. subtilis 168 genome (RefSeq accession number NC_000964.3) as the reference, differences with an absolute value of $\log _{2} \geq 1$ were accepted as significant. Selected genes were classified according to the SubtiWiki database categories [27]. The data discussed in this publication have been deposited in NCBI's Gene Expression Omnibus and are accessible through GEO Series accession number GSE106296.

\subsection{Validation using $q P C R$}

Five differentially expressed genes were selected for validation with qPCR using 16S ribosomal RNA, rrnA-16S, as the housekeeping gene. cDNAs were synthesized using QuantiTech Reverse Transcription Kit (Qiagen, Germany). Reactions were carried out using the formerly designed primers, as explained previously [24]. Fold changes were calculated according to the $2^{-\Delta \Delta \mathrm{CT}}$ method [28]. All reactions were performed with at least two technical replicates.

\subsection{Cell analysis with scanning electron microscopy}

Samples (control and berberine-roemerine treated cells) for SEM were prepared based on our previously reported protocol [29]. SEM images were obtained by Philips XL30 ESEMFEG/EDAX system (Philips, Holland) under high vacuum mode with $10 \mathrm{kV}$ energy and 3.0 spot size.

\subsection{Measurement of minimum inhibitory concentration and synergy}

Minimum inhibitory concentration (MIC) was measured using broth dilution method [30]. Serial two-fold dilutions of the berberine and roemerine were prepared in sterile 96-well U- 
bottomed plates; $50 \mu \mathrm{L}$ of the cell culture $\left(10^{5} \mathrm{CFU} / \mathrm{mL}\right)$ was deposited in each well in a total volume of $100 \mu \mathrm{L}$. MIC was evaluated with reference to control cells, mixed with DMSO or fresh growth media.

Checkerboard assay has been performed to determine the synergy between berberine and roemerine. In a U-bottom 96-well plate, as berberine was two-fold serially diluted horizontally, roemerine was two-fold serially diluted vertically. Dilution was achieved with fresh NB. Concentrations were kept in the range of $8-512 \mu \mathrm{g} \cdot \mathrm{mL}^{-1}$ for berberine and $4-256 \mu \mathrm{g} \cdot \mathrm{mL}^{-1}$ for roemerine. A control lane was prepared with DMSO. Then each well was mixed with an equal volume of cell suspensions to get an initial concentration of $5 \times 10^{5} \mathrm{CFU} / \mathrm{mL}$ in each well. Plates were incubated at $37^{\circ} \mathrm{C}$ for 24 hours without shaking.

The synergy between the compounds was evaluated by calculating the fractional inhibitory concentration index (FICI):

$$
\mathrm{FICI}=\sum_{i=1}^{n} \frac{M I C(\text { antimicrobial agent in combination })}{M I C(\text { antimicrobial agent alone })}
$$

FICI of $\leq 0.5$ means that the agents act synergistically; there is partial synergy when FICI is between 0.5 and 1.0; when FICI is $=1.0$, the effect is additive [31]. The MIC values were defined as the lowest concentrations showing no visible cell growth after 24 hours of incubation.

\subsection{Transport assay with BmrA}

Cloning, overexpression of recombinant BmrA in E. coli C41(DE3) cells, and preparation of inverted membrane vesicles were carried out as described previously [32]. The effect of roemerine on BmrA transport activity was monitored with Photon Technology International Quanta Master I Fluorimeter using doxorubicin as the substrate. The excitation and emission wavelengths were set at 480 and $590 \mathrm{~nm}$, respectively, for doxorubicin.

Inverted membrane vesicles ( $100 \mu \mathrm{g}$ of total protein) were added to a cuvette containing $50 \mathrm{mM}$ Hepes-KOH (pH 8.0), $8.5 \mathrm{mM} \mathrm{NaCl}, 4 \mathrm{mM}$ phosphoenolpyruvate, $60 \mu \mathrm{g}$ of pyruvate kinase, 2 
$\mathrm{mM} \mathrm{MgCl}_{2}$, and different concentrations of roemerine with a final volume of $1 \mathrm{~mL}$. After incubation for $1 \mathrm{~min}$ at $25{ }^{\circ} \mathrm{C}, 10 \mu \mathrm{M}$ of doxorubicin was added and its fluorescence was recorded for $\sim 1 \mathrm{~min}$. Then $2 \mathrm{mM}$ ATP was added and the fluorescence intensity was monitored for several minutes.

\section{Results and discussion}

Berberine has long been known as a natural product with significant antibacterial activity against Gram-positive and Gram-negative species [29]. Unfortunately, intracellular berberine concentrations usually remain below the effective values due to the activity of drug efflux pumps [33].

The current work undertakes the effort to find new EPIs by increasing the antibacterial activity of berberine in the model Gram-positive microorganism Bacillus subtilis. With this aim, the potential of three aporphine type alkaloids of plant origin, roemerine, boldine, and bulbocapnine, was tested for their pump inhibitory activities and then for their possible pump targets.

\subsection{Screening of the alkaloids for EPI properties}

The initial screening for the efflux pump inhibitory potential of the alkaloids was achieved by monitoring growth after treatment of the cells with the selected compounds.

The working concentrations of the EPI candidates were set at $25 \mu \mathrm{g} \cdot \mathrm{mL}^{-1}$, based on our previous report [24]. Roemerine itself acts as an antibacterial agent at high concentrations $\left(>50 \mu \mathrm{g} \cdot \mathrm{mL}^{-}\right.$ $\left.{ }^{1}\right)$ but at lower concentrations $\left(<25 \mu \mathrm{g} \cdot \mathrm{mL}^{-1}\right)$, its presence did not affect cell growth [20,24]. Similarly, when B. subtilis cells were grown in the presence of $25 \mu \mathrm{g} \cdot \mathrm{mL}^{-1}$ boldine or bulbocapnine, cell growth was not altered significantly (Fig. 2). While the growth rate of control cells was $0.65 \mathrm{hr}^{-1}$, the growth rates of the cells were constant between $0.59-0.63 \mathrm{hr}^{-1}$ after roemerine, boldine, and bulbocapnine treatments. 
Berberine working concentration was determined based on available literature. $250 \mu \mathrm{g} \cdot \mathrm{mL}^{-1}$ berberine totally ceased growth while $100 \mu \mathrm{g} \cdot \mathrm{mL}^{-1}$ significantly retarded growth [24]. On the other hand, $75 \mu \mathrm{g} \cdot \mathrm{mL}^{-1}$ berberine decreased the growth rate to $0.53 \mathrm{hr}^{-1}$ (Fig. 2). Our aim was to enhance the influence of berberine by conjugating it with an EPI, therefore $75 \mu \mathrm{g} \cdot \mathrm{mL}^{-1}$ was selected for further work.

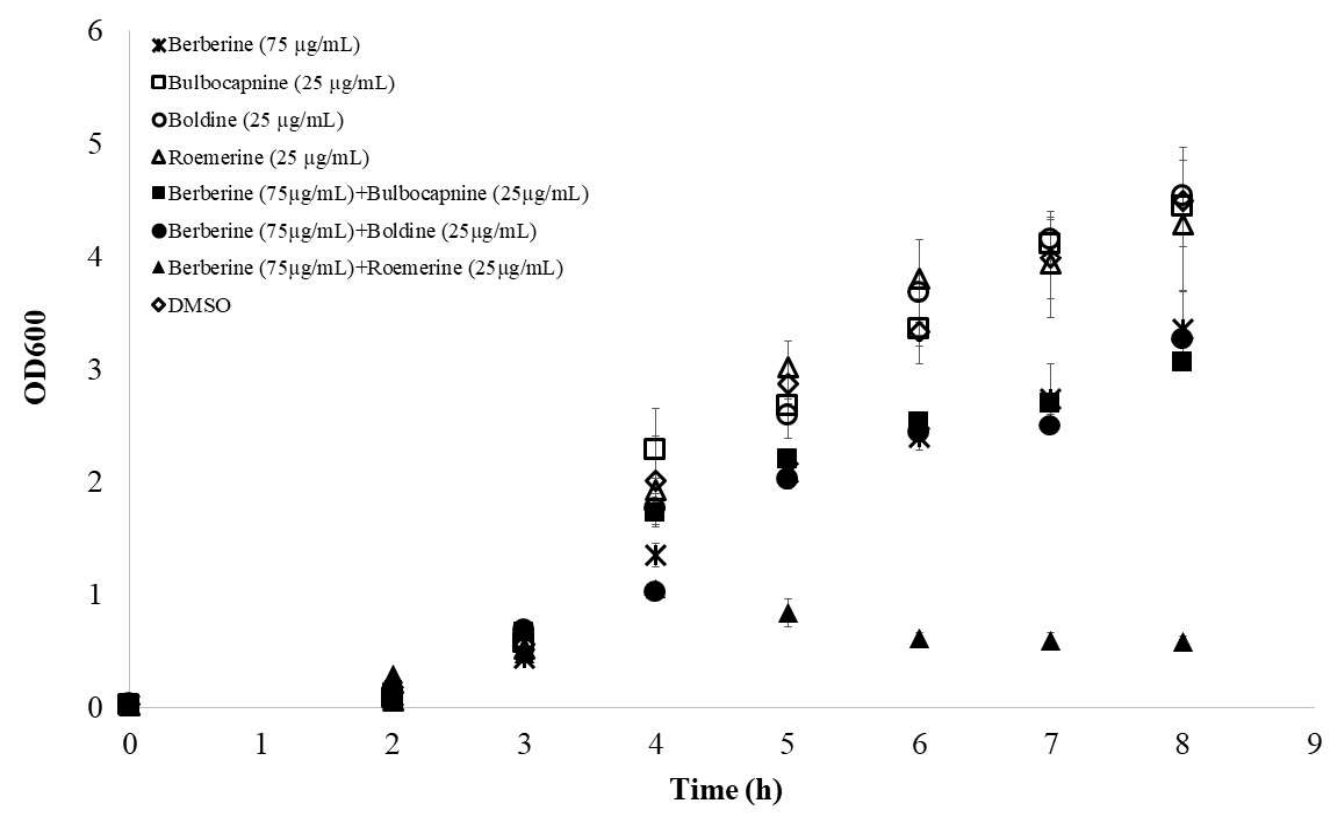

Fig. 2. Growth of wild-type B. subtilis cells in the presence of berberine and EPI candidates.

Finally, cells were treated with combinations of berberine and one of the alkaloids. Neither the berberine-boldine combination nor the berberine-bulbocapnine combination imposed a meaningful change on cell growth, in addition to that caused by only berberine. Growth rates lied between $0.42-0.45 \mathrm{hr}^{-1}$ in the presence of berberine-boldine and berberine-bulbocapnine combinations. On the other hand, the berberine-roemerine combination exhibited a significant synergistic effect on the cells. Cell growth almost completely ceased (Fig. 2), a finding similar to that found with $250 \mu \mathrm{g} \cdot \mathrm{mL}^{-1}$ berberine [24].

Berberine has long been known to be a substrate of drug efflux pumps. To enhance its biological activity, different strategies have been undertaken that includes the use of natural pump 
inhibitors such as the flavolignan 5'-MHC [34] or conjugation of berberine to a multidrug efflux pump inhibitor [21,35]. Thus, the synergism observed for the berberine and roemerine combination is a strong indication for the involvement of roemerine in the inhibition of efflux pump activities in B. subtilis. However, the multi-target feature of alkaloids suggests that roemerine may target more than one efflux pump. Further work was carried out with the berberine-roemerine combination to verify roemerine's potential as an EPI and elucidate its targets.

3.2. Scanning electron microscopy analysis of the cells treated with the berberineroemerine combination

The synergistic effect of berberine and roemerine on the cells was visualized by recording scanning electron microscopy (SEM) images (Fig. 3).
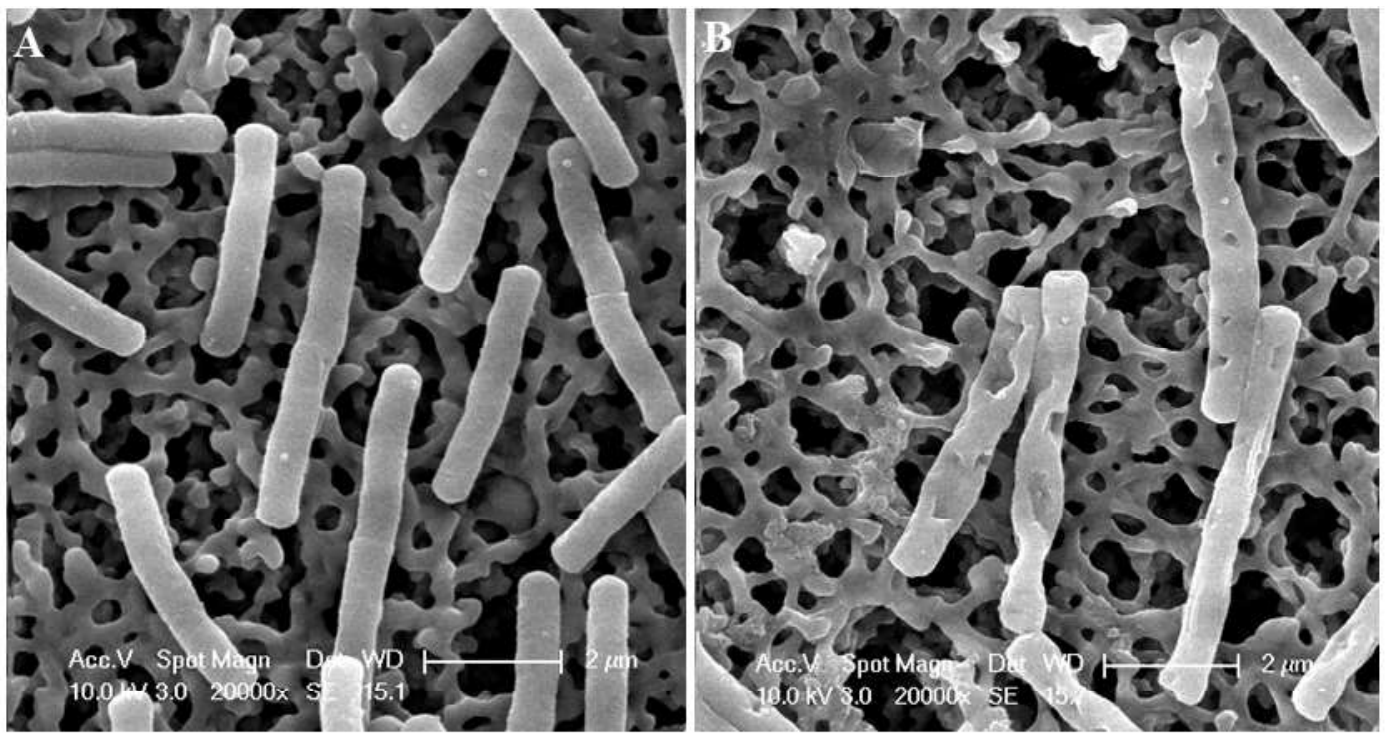

Fig. 3. Scanning electron microscopy images after one-hour treatment: A) control cells and B) cells with berberine $\left(75 \mu \mathrm{g} \cdot \mathrm{mL}^{-1}\right)$-roemerine $\left(25 \mu \mathrm{g} \cdot \mathrm{mL}^{-1}\right)$ combination treatment.

Control cells had shapes and sizes $(5.2 \pm 0.9 \mu \mathrm{m})$ characteristic of Bacillus species with smooth cell surfaces. After treatment of the cells with the berberine-roemerine combination, there were irregular dimples all over the surfaces. Furthermore, the cells were totally crumpled. The sizes 
of a total of 21 selected cells seemed to cluster into two groups: in the first group were 10 cells which were significantly shorter $(3.7 \pm 0.5 \mu \mathrm{m})$ and in the second group were 11 cells which were longer $(6.1 \pm 0.5 \mu \mathrm{m})$ than the controls.

In our previous work, we have reported increased cell sizes $(6.4 \pm 1.2 \mu \mathrm{m})$ with dimples on cell surfaces after berberine treatment [24]. Increased size is a well-known consequence for the presence of berberine since it blocks cell division by inhibiting cell division protein, FtsZ [36]. However, the second group of cells was remarkably shorter than the control cells. It is possible that this could be the effect of roemerine. Indeed, when B. subtilis cells were treated with 75 $\mu \mathrm{g} \cdot \mathrm{mL}^{-1}$ of only roemerine, there was significant retardation in growth and the cells were found to be shorter with blebs on surfaces [24]. There were no blebs on the surfaces of cells treated with the berberine and roemerine combination. Thus, the antimicrobial effect of roemerine was only partial at that concentration.

When the cells were treated with the berberine-roemerine combination, we hypothesize that roemerine enhanced the effect of berberine by maintaining a higher intracellular berberine concentration. SEM images showed that extensively distributed dimples were bigger and deeper with the combination treatment.

\subsection{Checkerboard assay of the berberine-roemerine combination}

The synergistic effect of the berberine-roemerine combination was further validated by the checkerboard assay. The MIC values of berberine and roemerine for B. subtilis cells were 256 and $64 \mu \mathrm{g} \cdot \mathrm{mL}^{-1}$, respectively (Table 1). The MIC values obtained for the $\Delta b m r A$ strain were identical with those obtained for the wild-type. On the other hand, for the $\Delta b m r$ strain, while the MIC value of roemerine remained unchanged, the MIC value of berberine dropped to 64 $\mu \mathrm{g} \cdot \mathrm{mL}^{-1}$. This sensitivity of the $\Delta b m r$ strain to berberine but not to roemerine strongly suggested that Bmr indeed effluxed berberine. 
The checkerboard assay showed that, when administered together, the effective concentrations of berberine and roemerine dropped to 64 and $16 \mu \mathrm{g} \cdot \mathrm{mL}^{-1}$. With these concentrations, the FICI value was calculated as 0.5 , meaning that these two alkaloids act synergistically.

Table 1. Summary of MIC of berberine and roemerine for different B. subtilis strains.

\begin{tabular}{lcc}
\hline & $\mathbf{M I C}_{\mathbf{b e r}}\left(\boldsymbol{\mu \mathbf { g } \cdot \mathbf { m L } ^ { - 1 } )}\right.$ & $\mathbf{M I C}_{\mathbf{r o e}}\left(\boldsymbol{\mu g} \cdot \mathbf{m L}^{-\mathbf{1}}\right)$ \\
\hline B. subtilis 168 & 256 & 64 \\
B. subtilis $(\Delta b m r)$ & 64 & 64 \\
B. subtilis $(\Delta b m r A)$ & 256 & 64 \\
\hline
\end{tabular}

\subsection{Transcriptomic analysis of the synergy in B. subtilis 168}

The synergistic effect of berberine and roemerine was then tackled by transcriptomic analysis. RNA-Seq results for the berberine-roemerine treated cells were comparatively analyzed with the available RNA-Seq data for control and berberine treated cells (GSE106296). Since the major task of using roemerine was to inhibit the efflux pumps, we speculated that the antimicrobial effect of berberine would be amplified in the cells treated with the combination. The statistics of the reads obtained from RNA-Seq analysis for the berberine and roemerine treated cells is given in Table 2. The transcripts were aligned taking $B$. subtilis 168 genome as the reference. Analysis has returned mapped reads over $90 \%$.

Table 2. Summary of read statistics results for control and alkaloid treated B. subtilis cDNA samples.

\begin{tabular}{lclccc}
\hline Treatment & $\begin{array}{c}\text { Read length } \\
(\mathbf{b p )}\end{array}$ & $\begin{array}{l}\text { Clean } \\
\text { Reads }\end{array}$ & $\begin{array}{c}\text { Clean } \\
\text { bases }\end{array}$ & $\begin{array}{l}\text { GC } \\
(\%)\end{array}$ & $\begin{array}{c}\text { Q20 } \\
(\%)\end{array}$ \\
\hline DMSO* $^{*}$ & 100 & 11128658 & 1112865800 & 44.60 & 98.6 \\
Berberine* $^{*}$ & 100 & 11083418 & 1108341800 & 43.91 & 93.2 \\
Berberine and roemerine & 100 & 11122254 & 1112225400 & 43.88 & 97.9 \\
\hline
\end{tabular}

* Data taken from Avci et al. [24]

Taking the absolute value of $\log _{2} \geq 1$ as significant, the reads were compared to the RNA-Seq obtained from control and $75 \mu \mathrm{g} \cdot \mathrm{mL}^{-1}$ berberine treated B. subtilis cells (GSE104946). The 
presence of the additional $25 \mu \mathrm{g} \cdot \mathrm{mL}^{-1}$ roemerine almost doubled the number of affected genes. While a total of 1305 genes were differentially expressed in berberine treated cells, a total of 2317 genes were differentially expressed in the presence of the combination. Of these genes, 995 were common in both cells, which demonstrated that about $75 \%$ of the differentially expressed genes with berberine, were also differentially expressed with the combination treatment.

Differentially expressed genes were categorized based on the information in SubtiWiki database is presented in Fig. 4. Based on their functions, some of the genes appear in more than one category.

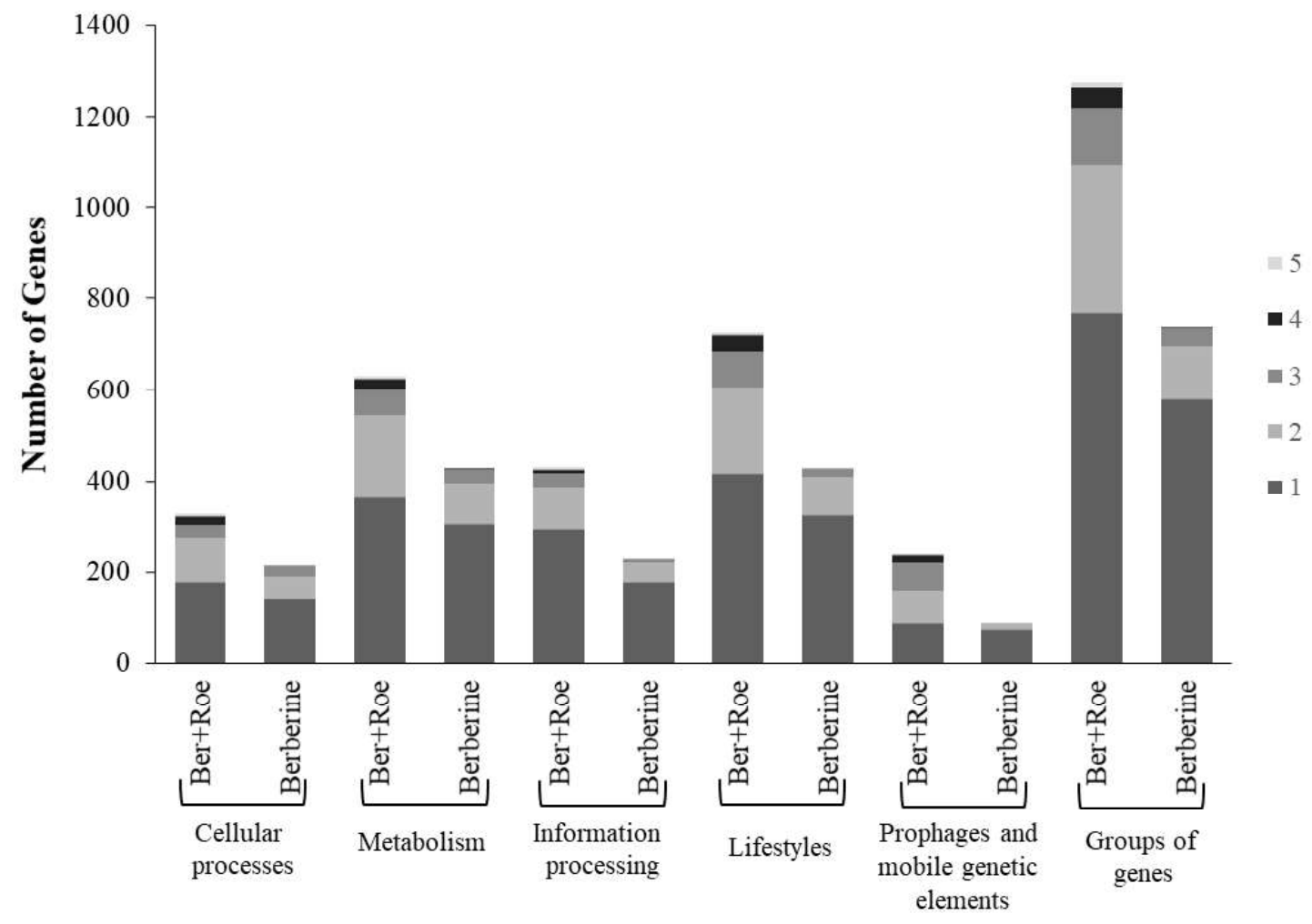

Fig. 4. Differentially expressed genes categorized based on the groupings in SubtiWiki database. The numbers that appear to the right of the plot indicate the absolute values of the fold changes in $\log _{2}$ scale.

In each category, the total number of affected genes was higher. Within each category, there 
was a noticeable increase in the number of genes with a fold change of 4 or higher in $\log _{2}$ scale. This difference was highest in the category of prophages and mobile genetic elements but most of those were 'y-genes'; thus their functions were unknown.

The increase in the number of up-regulated genes involved in genetic competence (information processing category of Figure 4) as we switch from the berberine treatment to the combination treatment provided a clear overview of the turmoil within the cell. Genetic competence, the uptake of genetic material from the surroundings, might serve to allow the use of extracellular DNA for nutritional purposes but it simultaneously has a role in genetic recombination. The latter contributes to making cells tolerant to antibiotics [37]. While the struggle for survival was at a basal level with berberine, mainly due to its efflux, this struggle became increasingly important in the combination treatment. Roemerine blocked berberine efflux, enabling intracellular berberine accumulation. Consequently, by inducing the genes of genetic competence, cells seek a way to overcome this unfavorable condition.

We have previously reported that berberine changed the expression of genes associated with the membrane, its synthesis and structural re-organization. Furthermore, genes encoding membrane proteins of diverse functions were also among the affected ones [24]. Treatment of the cells with the combination not only increased the number of genes but also the absolute value of their $\log _{2}$ values (Fig. 4). Specifically, genes encoding proteins involved in cell wall synthesis, modification, turn-over, and recycling, genes encoding proteins of the biosynthesis of cell wall polymers, teichoic and teichuronic acids, and genes encoding proteins of the cell envelope such as carboxypeptidases, transpeptidases, and endopeptidases were among the highly affected targets.

An extensive number of genes encoding transporters, most of which were up-regulated, were affected with berberine treatment [24]. This number increased remarkably in the combination treatment. These transporters included but were not limited to, amino acid and oligopeptide 
transporters, metal ion transporters, compatible solute transporters, and sugar transporters. Not only transporters of nutrient uptake but also transporters of TCA cycle intermediates (citrate, fumarate, malate, and alpha-keto-glutarate) seemed to be influenced especially under berberineroemerine treatment as if the cells were in a state of nutrient limitation [38]. Since stress conditions were found to trigger the synthesis of various transporters [39], this finding was not unexpected.

A key strategy followed specifically by low $\mathrm{G}+\mathrm{C}$ Gram-positive (i.e. Firmicutes) bacteria under harsh environmental conditions is spore formation, in addition to the increase in stress related proteins. The genes such as those encoding spore crust assembly, germination, and maturation of this tightly regulated network increased both in number and fold changes with the combination treatment. It may, however, take several hours for the cells to form such endospores [40] and, for this reason, most of the cells died before this process could take place, as evidenced by SEM images. Furthermore, berberine accumulation in the combination treatment also triggered the expression of many genes related to survival and protection against stress conditions.

RNA-Seq data were finally validated using quantitative polymerase chain reaction (qPCR). The five genes selected from different pathways showed that the regulation pattern of all the selected genes was consistent, though with variations in the absolute values of the fold changes (Table 3). These kinds of variations commonly arise as a result of statistics in RNA-Seq (i.e. the high variability across samples causes loss in statistical significance). Furthermore, in qPCR, genes are normalized with respect to the housekeeping gene whereas RNA-Seq uses internal normalization using geometrical averages. 
Table 3. Expression levels of selected genes.

\begin{tabular}{ccc}
\hline Gene name & Pathway involved & $\begin{array}{c}\text { Regulation pattern } \\
\text { /log2 fold change } \\
\text { (qPCR / RNA-Seq) }\end{array}$ \\
\hline$d h b B$ & Fe uptake and metabolism & $3.1 / 1.5$ \\
$f e u A$ & Fe uptake and metabolism & $3.6 / 3.5$ \\
$b m r$ & Multidrug transporter & $6.2 / 1.1$ \\
narH & $\begin{array}{c}\text { Anaerobic respiration and proton } \\
\text { motive force (PMF) generation }\end{array}$ & $\mathrm{BDL} /-4.5$ \\
& $\begin{array}{c}\text { Aromatic amino acid } \\
\text { biosynthesis }\end{array}$ & $-0.9 /-2.5$ \\
\hline
\end{tabular}

BDL: Below detection limits

\subsection{Identification of roemerine efflux pump targets}

B. subtilis has an abundant number of well-characterized efflux pumps including BceAB [41], BmrA [9], BmrCD [42,43] of the ABC superfamily; Blt [44,45], Bmr [44-46], Bmr3 [47,48], LmrB [49,50], and MdtP [51] of the MFS superfamily; YerP [52] of resistance-nodulation-cell division (RND) superfamily, and EbrAB [53] of the small multidrug resistance (SMR) superfamily. Among these, Bmr is one of the first-discovered bacterial efflux pumps and Blt is another that is highly homologous to $\mathrm{Bmr}(52 \%$ sequence identity) $[13,54]$.

The work by You et al. suggested that roemerine increases the cytotoxicity of vinblastine in multidrug-resistant KB-V1 cells by interacting with the eukaryotic multidrug resistance (MDR) pump, P-glycoprotein [15]. Since BmrA is the prokaryotic homologue of P-glycoprotein in $B$. subtilis [9], we speculated that roemerine could bind and inhibit this efflux pump. On the other hand, berberine has been proven to be a substrate of the NorA pump of Staphylococcus aureus [34]. Thus, Bmr of B. subtilis, a close homologue of NorA, might promote active berberine efflux in these cells $[55,56]$. Indeed both the MIC values and the synergism of berberine and roemerine point to the inhibition of Bmr by roemerine. Furthermore, since many pump inhibitors target more than one pump, both BmrA and Bmr may also be simultaneously inhibited by roemerine. To this end, we focused on the two KO mutants of B. subtilis cells, 
$\Delta b m r$ and $\Delta b m r A$, with the motivation to find whether these pumps are targeted by roemerine.

The effect of the berberine-roemerine combination on the growth of these two mutants has been presented in Fig. 5.

The growth rates of the control and $25 \mu \mathrm{g} \cdot \mathrm{mL}^{-1}$ roemerine treated mutant strains were similar to that of the wild-type, between $0.59-0.63 \mathrm{hr}^{-1}$. When the $\Delta b m r \mathrm{~A}$ strain was treated with 75 $\mu \mathrm{g} \cdot \mathrm{mL}^{-1}$ berberine alone, growth was only slightly retarded. Growth rate indeed decreased to $0.44 \mathrm{hr}^{-1}$, a slightly lower value than obtained with the wild-type cells. When this mutant strain was treated with the combination, growth almost completely ceased, as in the wild-type. The behavior of the $\Delta b m r$ strain was totally different; $75 \mu \mathrm{g} \cdot \mathrm{mL}^{-1}$ berberine alone was sufficient to cease growth (Fig. 5). Actually, this could be foreseen since berberine concentration was already above the MIC.

Checkerboard assay and combination treatments (Fig. 2) together with growths of mutant strains (Fig. 5) strongly suggested that, in the wild-type strain, roemerine inhibited berberine efflux by blocking the Bmr pump. The absence of the Bmr pump facilitated the accumulation of higher intracellular berberine; thus, in the $\Delta b m r$ strain, berberine was able to display its antimicrobial effect at lower concentrations. Indeed, the MIC value of berberine obtained for the $\Delta b m r$ strain was $64 \mu \mathrm{g} \cdot \mathrm{mL}^{-1}$ (Table 1), $1 / 4 \mathrm{MIC}$ of the value obtained for the wild type. The findings obtained with the $\Delta b m r A$ strain from the growth profiles were less obvious. The MIC values obtained for the $\Delta b m r A$ strain were identical with of the wild-type (Table 1). The effect of $75 \mu \mathrm{g} \cdot \mathrm{mL}^{-1}$ berberine was somewhat superior in the $\Delta b m r A$ strain when compared to the wild type, which could mean that although the major berberine efflux is mediated through Bmr, a minor amount may possibly be effluxed through BmrA. An evidence for this was found also in the RNA-Seq analysis of the wild-type strain. Upon berberine and berberine-roemerine treatments, there was an expressional change of 1.5 and $1.1\left(\log _{2}\right.$ scale) in Bmr, respectively, whereas the expressional change in BmrA was insignificant under the same 


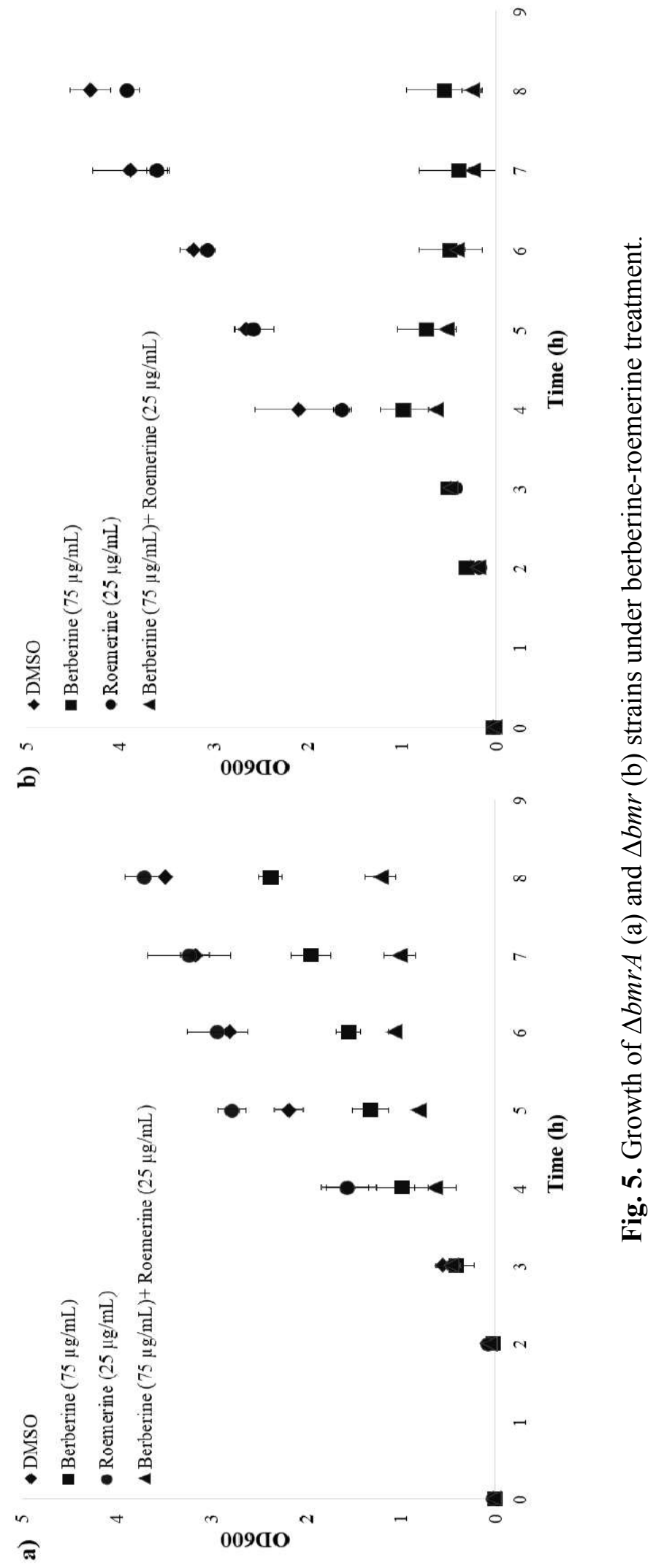


conditions. Whereas BmrA was found to be constitutively expressed during the growth phase of B. subtilis [9], Bmr was found to be down-regulated by BmrR [57]. If the repression of Bmr by BmrR could be alleviated by berberine, this might explain the results found here.

The work with the mutant strains demonstrated that roemerine inhibited Bmr, but it was not sufficient to state whether or not roemerine inhibited the BmrA pump. Owing to the fact that the work with the mutants could not convey much information the inhibition of BmrA by roemerine, transport assays using BmrA overexpressed in E. coli inverted membrane vesicles were conducted. To this end, transport of the BmrA substrate doxorubicin was followed by measuring its fluorescence intensity. The findings showed that after incubation of the prepared membranes with increasing concentrations of roemerine, doxorubicin transport notably decreased (Fig. 6). This was a strong indication of the direct inhibition of BmrA by roemerine.

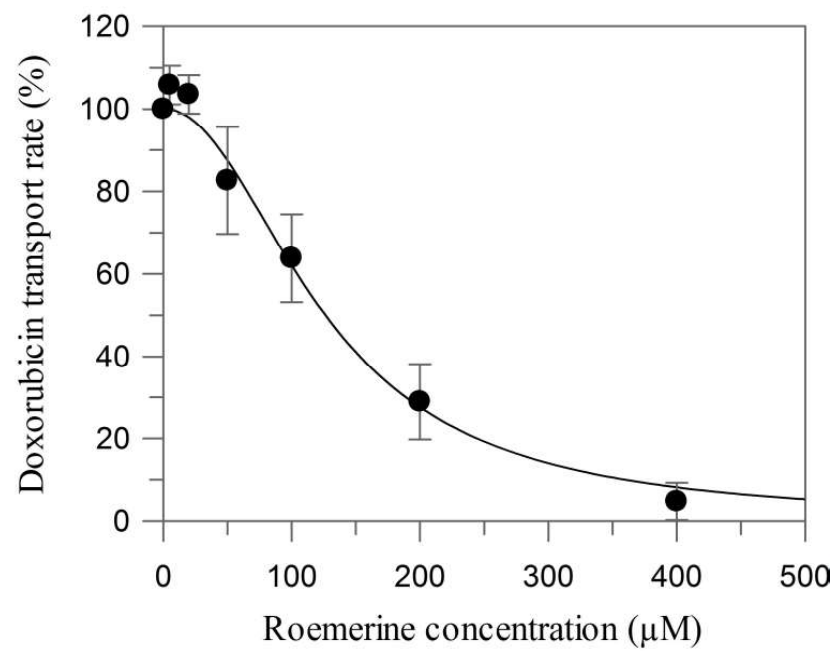

Fig. 6. Inhibition of doxorubicin transport by roemerine. E. coli inverted membrane vesicles overexpressing BmrA were assayed for doxorubicin $(10 \mu \mathrm{M})$ transport in the presence of increasing concentrations of roemerine. Doxorubicin transport was measured by fluorescence, as previously described [9], and transport rates were calculated by initial slopes following ATP addition [22]. IC50 was calculated at $126 \pm 8 \mu \mathrm{M}$ with GraFit version 7 software. Data represent the average of 3 independent experiments with standard deviation. 


\section{Conclusions}

MDR pumps are important contributors in all organisms for gaining resistance through extrusion of multiple compounds such as antibiotics and anticancer drugs [54,58]. This efflux minimizes the intracellular accumulation of drugs, increasing their effective concentrations. Thus, inhibition of MDR pumps is an attractive approach for revitalization of drugs of low efficacy due to their efflux.

The current work repurposed the bioactive alkaloid roemerine as a potential efflux pump inhibitor. In B. subtilis cells, both Bmr belonging to the MFS superfamily and BmrA belonging to the ABC superfamily were found to be inhibited by the bioactive alkaloid roemerine. SEM and RNA-Seq analysis showed that roemerine potentiated the effect of berberine by helping to maintain an effective intracellular berberine concentration. Evaluated growth rates and checkerboard assays confirmed that roemerine and berberine acted synergistically and that roemerine prevented berberine efflux by inhibiting the Bmr efflux pump. Finally, transport assays conducted using E. coli inverted membrane vesicles overexpressing BmrA confirmed that increasing concentrations of roemerine inhibited the transport of the BmrA substrate, doxorubicin, through this pump. Thus, we demonstrated that conjugation of roemerine to substrates of efflux pumps, Bmr and BmrA may potentiate the activity of these molecules. Furthermore, this would allow the administration of roemerine well below its cytotoxicity limits.

\section{Acknowledgements}

This work was supported by TUBITAK (The Scientific and Technological Research Council of Turkey) Research Grant 113M052 (BSA), Marmara University, Scientific Research Projects Committee Research Grant FEN-B-120917-0534 (BSA) and FEN-C-YLP-070317-0110 (BSA). FGA was supported by FEMS Research Grant. 


\section{Conflict of interest}

The authors declare no conflict of interest.

\section{References}

[1] D. Du, X. Wang-Kan, A. Neuberger, H.W. van Veen, K.M. Pos, L.J.V. Piddock, B.F. Luisi, Multidrug efflux pumps: structure, function and regulation, Nat. Rev. Microbiol. 16 (2018) 523-539. doi:10.1038/s41579-018-0048-6.

[2] J. Jin, G. Hua, Z. Meng, P. Gao, Antibacterial mechanisms of berberine and reasons for little resistance of bacteria, Chinese Herb. Med. 3 (2011) 27-35. doi:10.3969/j.issn.16746384.2011.01.007.

[3] M. Stavri, L.J.V Piddock, S. Gibbons, Bacterial efflux pump inhibitors from natural sources, J. Antimicrob. Chemother. 59 (2007) 1247-1260. doi:10.1093/jac/dk1460.

[4] P.W. Limaverde, F.F. Campina, F.A.B. da Cunha, F.D. Crispim, F.G. Figueredo, L.F. Lima, et al. Inhibition of the TetK efflux-pump by the essential oil of Chenopodium ambrosioides L. and $\alpha$-terpinene against Staphylococcus aureus IS-58, Food Chem. Toxicol. 109 (2017) 957-961. doi:10.1016/j.fct.2017.02.031.

[5] S. Prasch, F. Bucar, Plant derived inhibitors of bacterial efflux pumps: an update, Phytochem. Rev. 14 (2015) 961-974. doi:10.1007/s11101-015-9436-y.

[6] H.Y. Mahmood, S. Jamshidi, J.M. Sutton, K.M. Rahman, Current Advances in Developing Inhibitors of Bacterial Multidrug Efflux Pumps, Curr. Med. Chem. 23 (2016) 1062-1081. doi:10.2174/0929867323666160304150522.

[7] S.O. Sewanu, M.C. Bongekile, O.O. Folusho, L.O. Adejumobi, O.A. Rowland, Antimicrobial and efflux pumps inhibitory activities of Eucalyptus grandis essential oil against respiratory tract infectious bacteria, J. Med. Plants Res. 9 (2016) 343-348. doi:10.5897/JMPR2015.

[8] O. Lomovskaya, M.S. Warren, A. Lee, J. Galazzo, R. Fronko, M. Lee, et al. Identification 
and characterization of inhibitors of multidrug resistance efflux pumps in Pseudomonas aeruginosa: Novel agents for combination therapy, Antimicrob. Agents Chemother. 45 (2001) 105-116. doi:10.1128/AAC.45.1.105-116.2001.

[9] E. Steinfels, C. Orelle, J.R. Fantino, O. Dalmas, J.L. Rigaud, F. Denizot, et al. Characterization of $\mathrm{YvcC}(\mathrm{BmrA})$, a multidrug $\mathrm{ABC}$ transporter constitutively expressed in Bacillus subtilis, Biochemistry. 43 (2004) 7491-7502. doi:10.1021/bi0362018.

[10] A.A. Neyfakh, C.M. Borsch, G.W. Kaatz, Fluoroquinolone Resistance Protein NorA of Staphylococcus aureus is a Multidrug Efflux Transporter, Antimicrob. Agents Chemother. 37 (1993) 128-129. doi:10.1128/aac.37.1.128.

[11] M.I. Garvey, L.J.V Piddock, The Efflux Pump Inhibitor Reserpine Selects MultidrugResistant Streptococcus pneumoniae Strains that Overexpress the ABC Transporters PatA and PatB, Antimicrob. Agents Chemother. 52 (2008) 1677-1685. doi:10.1128/AAC.01644-07.

[12] S. Gibbons, E. Udo, The effect of reserpine, a modulator of multidrug efflux pumps, on the in vitro activity of tetracycline against clinical isolates of methicillin resistant Staphylococcus aureus (MRSA) possessing the tet(K) determinant, Phyther. Res. 14 (2000) 139-140.

[13] A.A. Neyfakh, V.E. Bidnenko, L.B. Chen, Efflux-mediated multidrug resistance in Bacillus subtilis: similarities and dissimilarities with the mammalian system., Proc. Natl. Acad. Sci. U. S. A. 88 (1991) 4781-5. doi:10.1073/pnas.88.11.4781.

[14] R. Kumar, S. Jandaik, P. Patial, A Review on Efflux Pump Inhibitors of Gram-Positive and Gram-Negative Bacteria from Plant Sources, Int. J. Curr. Microbiol. Appl. Sci. 5 (2016) 837-855. doi:10.20546/ijcmas.2016.506.092.

[15] M. You, D.B. Mahinda Wickramaratne, G.L. Silva, H. Chai, T.E. Chagwedera, N.R. Farnsworth, et al. (-)-Roemerine, an aporphine alkaloid from annona senegalensis that 
reverses the multidrug-resistance phenotype with cultured cells, J. Nat. Prod. 58 (1995) 598-604. doi:10.1021/np50118a021.

[16] A. Zhang, Y. Zhang, A.R. Branfman, R.J. Baldessarini, J.L. Neumeyer, Advances in development of dopaminergic aporphinoids, J. Med. Chem. 50 (2007) 171-181. doi:10.1021/jm060959i.

[17] A. Adsersen, A. Kjølbye, O. Dall, A.K. Jäger, Acetylcholinesterase and butyrylcholinesterase inhibitory compounds from Corydalis cava Schweigg. \& Kort, J. Ethnopharmacol. 113 (2007) 179-182. doi:10.1016/j.jep.2007.05.006.

[18] Y.H. Zhang, J.S. Shin, S.S. Lee, S.H. Kim, M.K. Lee, Inhibition of tyrosine hydroxylase by bulbocapnine, Planta Med. 63 (1997) 362-363. doi:10.1055/s-2006-957702.

[19] M. Miski, X. Shen, R. Cooper, A.M. Gillum, D.K. Fisher, R.W. Miller, T.I. Higgins, Aporphine Alkaloids, CD45 Protein Tyrosine Phosphatase Inhibitors, from Rollinia ulei, Bioorg. Med. Chem. Lett. 5 (1995) 1519-1522.

[20] N. Budeyri Gokgoz, B. Sariyar Akbulut, Proteomics Evidence for the Activity of the Putative Antibacterial Plant Alkaloid (-)-Roemerine: Mainstreaming Omics-Guided Drug Discovery, Omi. A J. Integr. Biol. 19 (2015) 478-489. doi:10.1089/omi.2015.0056.

[21] A.R. Ball, G. Casadei, S. Samosorn, J.B. Bremner, F.M. Ausubel, T.I. Moy, K. Lewis, Conjugating berberine to a multidrug resistance pump inhibitor creates an effective antimicrobial, ACS Chem. Biol. 1 (2006) 594-600. doi:10.1021/cb600238xCCC:33.50.

[22] K. Mathieu, W. Javed, S. Vallet, C. Lesterlin, M.P. Candusso, F. Ding, et al. Functionality of membrane proteins overexpressed and purified from E. coli is highly dependent upon the strain, Sci. Rep. 9 (2019) 2654. doi:10.1038/s41598-019-39382-0.

[23] H. Guinaudeau, M. Leboeuf, A. Cave, Aporphine Alkaloids, Lloydia. 38 (1975) $275-$ 338.

[24] F.G. Avci, N.A. Sayar, B. Sariyar Akbulut, An OMIC approach to elaborate the 
antibacterial mechanisms of different alkaloids, Phytochemistry. 149 (2018). doi:10.1016/j.phytochem.2017.12.023.

[25] B. Langmead, C. Trapnell, M. Pop, S.L. Salzberg, Ultrafast and memory-efficient alignment of short DNA sequences to the human genome, Genome Biol. (2009). doi:10.1186/gb-2009-10-3-r25.

[26] M.I. Love, W. Huber, S. Anders, Moderated estimation of fold change and dispersion for RNA-seq data with DESeq2, Genome Biol. (2014). doi:10.1186/s13059-014-05508.

[27] B. Zhu, SubtiWiki in 2018 : from genes and proteins to functional network annotation of the model organism Bacillus subtilis, 46 (2018) 743-748. doi:10.1093/nar/gkx908.

[28] K.J. Livak, T.D. Schmittgen, Analysis of relative gene expression data using real-time quantitative PCR and, Methods. 25 (2001) 402-408. doi:10.1006/meth.2001.1262.

[29] N. Budeyri Gokgoz, F.G. Avci, K.K. Yoneten, B. Alaybeyoglu, E. Ozkirimli, N.A. Sayar, et al. Response of Escherichia coli to Prolonged Berberine Exposure, Microb. Drug Resist. 23 (2017). doi:10.1089/mdr.2016.0063.

[30] D. Amsterdam, Susceptibility testing of antimicrobials in liquid media, in: V. Loman (Ed.), Antibiotics in Laboratory Medicine, Williams and Wilkins, Baltimore, 1996: pp. $51-111$.

[31] Y. Cai, R. Wang, F. Pei, B.B. Liang, Antibacterial activity of allicin alone and in combination with $\beta$-lactams against Staphylococcus spp. and Pseudomonas aeruginosa, J. Antibiot. (Tokyo). 60 (2007) 335-338. doi:10.1038/ja.2007.45.

[32] E. Steinfels, C. Orelle, O. Dalmas, F. Penin, B. Miroux, A. Di Pietro, J.M. Jault, Highly efficient over-production in E. coli of $\mathrm{YvcC}$, a multidrug-like ATP-binding cassette transporter from Bacillus subtilis, Biochim. Biophys. Acta - Biomembr. 1565 (2002) 15. doi:10.1016/S0005-2736(02)00515-1. 
[33] S. Wang, J. Yu, M. Suvira, P. Setlow, Y.Q. Li, Uptake of and resistance to the antibiotic berberine by individual dormant, germinating and outgrowing bacillus spores as monitored by laser tweezers raman spectroscopy, PLoS One. 10 (2015). doi:10.1371/journal.pone.0144183.

[34] F.R. Stermitz, P. Lorenz, J.N. Tawara, L.A. Zenewicz, K. Lewis, Synergy in a medicinal plant: Antimicrobial action of berberine potentiated by 5'-methoxyhydnocarpin, a multidrug pump inhibitor, Proc. Natl. Acad. Sci. 97 (2000) 1433-1437. doi:10.1073/pnas.030540597.

[35] S. Samosorn, B. Tanwirat, N. Muhamad, G. Casadei, D. Tomkiewicz, K. Lewis, et al. Antibacterial activity of berberine-NorA pump inhibitor hybrids with a methylene ether linking group, Bioorganic Med. Chem. $17 \quad$ (2009) 3866-3872. doi:10.1016/j.bmc.2009.04.028.

[36] J.M. Boberek, J. Stach, L. Good, Genetic evidence for inhibition of bacterial division protein FtsZ by berberine, PLoS One. 5 (2010). doi:10.1371/journal.pone.0013745.

[37] M. Blokesch, Natural competence for transformation, Curr. Biol. 26 (2016) R1126R1130. doi:10.1016/j.cub.2016.08.058.

[38] T. Ferenci, Regulation by nutrient limitation, Curr. Opin. Microbiol. 2 (1999) 208-213. doi:10.1016/S1369-5274(99)80036-8.

[39] K. Shimizu, Regulation Systems of Bacteria such as Escherichia coli in Response to Nutrient Limitation and Environmental Stresses, Metabolites. 4 (2014) 1-35. doi:10.3390/metabo4010001.

[40] J.E. González-Pastor, E.C. Hobbs, R. Losick, Cannibalism by sporulating bacteria, Science. 301 (2003) 510-513. doi:10.1126/science.1086462.

[41] R. Ohki, Giyanto, K. Tateno, W. Masuyama, S. Moriya, K. Kobayashi, N. Ogasawara, The BceRS two-component regulatory system induces expression of the bacitracin 
transporter, BceAB, in Bacillus subtilis, Mol. Microbiol. 49 (2003) 1135-1144. doi:10.1046/j.1365-2958.2003.03653.x.

[42] C. Torres, C. Galián, C. Freiberg, J.R. Fantino, J.M. Jault, The YheI/YheH heterodimer from Bacillus subtilis is a multidrug $\mathrm{ABC}$ transporter, Biochim. Biophys. Acta Biomembr. 1788 (2009) 615-622. doi:10.1016/j.bbamem.2008.12.012.

[43] R. Bernard, P. Joseph, A. Guiseppi, M. Chippaux, F. Denizot, YtsCD and YwoA, two independent systems that confer bacitracin resistance to Bacillus subtilis, FEMS Microbiol. Lett. 228 (2003) 93-97. doi:10.1016/S0378-1097(03)00738-9.

[44] M. Ahmed, L. Lyass, P.N. Markham, S.S. Taylor, N. Vazquez-Laslop, A.A. Neyfakh, Two highly similar multidrug transporters of Bacillus subtilis whose expression is differentially regulated, J. Bacteriol. 177 (1995) 3904-3910.

[45] N.N. Baranova, A. Danchin, A.A. Neyfakh, Mta, a global MerR-type regulator of the Bacillus subtilis multidrug-efflux transporters., Mol. Microbiol. 31 (1999) 1549-1559. doi:10.1046/j.1365-2958.1999.01301.x.

[46] D.P. Woolridge, N. Vazquez-Laslop, P.N. Markham, M.S. Chevalier, E.W. Gerner, A.A. Neyfakh, Efflux of the Natural Polyamine Spermidine Facilitated by the Bacillus subtilis Multidrug Transporter Blt, Biochemistry. (1997) 8864-8866. doi:10.1074/jbc.272.14.8864.

[47] R. Ohki, M. Murata, bmr3, a third multidrug transporter gene of Bacillus subtilis., J. Bacteriol. 179 (1997) 1423-1427.

[48] R. Ohki, K. Tateno, Increased stability of bmr3 mRNA results in a multidrug-resistant phenotype in Bacillus subtilis, J. Bacteriol. $186 \quad$ (2004) 7450-7455. doi:10.1128/JB.186.21.7450-7455.2004.

[49] K.I. Yoshida, Y.H. Ohki, M. Murata, M. Kinehara, H. Matsuoka, T. Satomura, et al. Bacillus subtilis LmrA is a repressor of the $\operatorname{lmrAB}$ and yxaGH operons: Identification of 
its binding site and functional analysis of $1 \mathrm{mrB}$ and yxaGH, J. Bacteriol. 186 (2004) 5640-5648. doi:10.1128/JB.186.17.5640-5648.2004.

[50] M. Murata, S. Ohno, M. Kumano, K. Yamane, R. Ohki, Multidrug resistant phenotype of Bacillus subtilis spontaneous mutants isolated in the presence of puromycin and lincomycin, Can. J. Microbiol. 49 (2003) 71-77. doi:10.1139/w03-014.

[51] J.Y. Kim, T. Inaoka, K. Hirooka, H. Matsuoka, M. Murata, R. Ohki, et al. Identification and characterization of a novel multidrug resistance operon, mdtRP (yusOP), of Bacillus subtilis, J. Bacteriol. 191 (2009) 3273-3281. doi:10.1128/JB.00151-09.

[52] K. Tsuge, Y. Ohata, M. Shoda, Gene yerP, involved in surfactin self-resistance in Bacillus subtilis, Antimicrob. Agents Chemother. 45 (2001) 3566-3573. doi:10.1128/AAC.45.12.3566-3573.2001.

[53] Y. Masaoka, Y. Ueno, Y. Morita, T. Kuroda, A Two-Component Multidrug Efflux Pump, EbrAB, in Bacillus subtilis, J. Bacteriol. 182 (2000) 2307-2312. doi:10.1128/JB.182.8.2307-2310.2000.Updated.

[54] B.D. Schindler, G.W. Kaatz, Multidrug efflux pumps of gram-positive bacteria, Drug Resist. Updat. 27 (2016) 1-13. doi:10.1016/j.drup.2016.04.003 1368-7646/C).

[55] M. Ahmed, C.M. Borsch, A.A. Neyfakh, S. Schuldiner, Mutants of the Bacillus subtilis multidrug transporter Bmr with altered sensitivity to the antihypertensive alkaloid reserpine, J. Biol. Chem. 268 (1993) 11086-11089.

[56] M. Tillhon, L.M. Guamán Ortiz, P. Lombardi, A.I. Scovassi, Berberine: New perspectives for old remedies, Biochem. Pharmacol. 84 (2012) 1260-1267. doi:10.1016/j.bcp.2012.07.018.

[57] M. Ahmed, M. Borsch, S.S. Taylor, N. Vazquez-Laslop, A.A. Neyfakh, A Protein That Activates Expression of a Multidrug Efflux Transporter upon Binding the Transporter Substrates, 269 (1994) 28506-28513. 
[58] H. Nikaido, Multidrug Resistance in Bacteria, Annu Rev Biochem. (2009) 119-146. doi:10.1146/annurev.biochem.78.082907.145923.Multidrug. 


\section{Conflict of interest}

The authors declare no conflict of interest. 